\title{
Clinical Correlates of Weight Loss and Attrition During a 10-Week Dietary Intervention Study: Results from the NUGENOB Project
}

\author{
Teodora Handjieva-Darlenska ${ }^{a}$ b Claus Holst $^{c}$ Katrine Grau ${ }^{c, d}$ \\ Ellen Blaak ${ }^{\mathrm{e}}$ J.Alfredo Martinez ${ }^{\mathrm{f}}$ Jean-Michel Oppertg Moira A. Taylor $^{\mathrm{h}}$ \\ Thorkild I.A. Sørensen ${ }^{c}$ Arne Astrup ${ }^{b}$ \\ ${ }^{a}$ National Multiprofile Transport Hospital, Sofia, Bulgaria, ${ }^{b}$ Department of Human Nutrition, \\ Exercice and Sports, Faculty of Life Sciences, University of Copenhagen, 'Institute of Preventive \\ Medicine, Copenhagen University Hospitals, dDepartment of Epidemiology Research, Statens \\ Serum Institute, Copenhagen, Denmark, e Department of Human Biology, NUTRIM School for \\ Nutrition, Toxicology and Metabolism Maastricht University Medical Centre+, Maastricht, the \\ Netherlands, ${ }^{f}$ Department of Physiology and Nutrition, University of Navarra, Pamplona, Spain, \\ 9 Department of Nutrition, Pitie-Salpetriere Hospital (AP-HP), University Pierre et Marie Curie- \\ Paris6, Centre for Research on Human Nutrition Ile-De-France (CRNH IdF), Paris, France, ${ }^{\text {h School }}$ \\ of Biomedical Sciences University of Nottingham Medical School, Queen's Medical Centre, \\ Nottingham, UK
}

\section{Key Words}

Correlates $\cdot$ Early weight loss $\cdot$ Half-way weight loss $\cdot$ Attrition $\cdot$ Gender

\begin{abstract}
Objective: The aim of this study was to identify the pre-treatment subject characteristics and weight loss changes as determinants of weight loss and attrition during a 10-week dietary intervention study. Methods: A total of 771 obese subjects (BMI $35.6 \mathrm{~kg} / \mathrm{m}^{2}$ ) of both genders were included from 8 clinical centres in 7 European countries, who underwent a 10-week dietary intervention study comparing two hypo-energetic (-600 kcal/day) diets varying in fat content. Results: The multiple regression model showed that weight loss at week 10 was predicted by: $6.55+1.27 \times$ early weight loss $(\mathrm{kg})$ at week $1+1.35 \times$ gender $\left(R^{2}=0.28, p<\right.$ 0.001 ). When performing the corresponding model with half-way weight loss (week 5 ) as covariate, the regression equation was: weight loss $(\mathrm{kg})$ at week $10=1.88+1.38 \times$ half-way weight loss $(\mathrm{kg})($ week 5$)+0.42 \times$ gender $\left(R^{2}=0.77, p<0.001\right)$. A cut-off target of $\geq 4 \mathrm{~kg}$ weight loss at week 5 emerged as an optimal predictor for reaching at least $10 \%$ weight loss at week 10. Greater attrition likelihood was predicted by high-fat diet, decreased early and half-way weight losses. Conclusion: Early and half-way weight losses are associated with and could contribute to prediction of the final weight loss and attrition.
\end{abstract}

Copyright $\odot 2012$ S. Karger GmbH, Freiburg

Dr. Teodora Handjieva-Darlenska

Department of Pharmacology and Toxicology

Medical Faculty, Medical University

2 Zdrave, Str., 1431 Sofia (Bulgaria)

teodorah@abv.bg 
Handjieva-Darlenska et al.: Clinical Correlates of Weight Loss and Attrition During a

10-Week Dietary Intervention Study: Results from the NUGENOB Project

\section{Introduction}

Obesity prevalence is increasing world-wide with a high incidence of numerous co-morbidities $[1,2]$. It is well accepted that a $5-10 \%$ decrease in body weight reduces the cardiovascular and metabolic health risks associated with obesity [3, 4]. The success of body weight management is influenced by the net result of the complex interplay between behavioural, hormonal, genetic and metabolic components. Weight loss varies between individuals participating in the same programme [4]. Thereafter, it is of great clinical interest and importance to identify individual determinants of weight loss, especially, pre-treatment moderators that predict subjects who are likely to be successful and factors that might suggest how medical practice could be modified to improve outcome. Substantial efforts have been devoted to determine individual characteristics that would predict body weight loss in overweight/obese subjects $[5,6]$. Several studies have suggested psychological, behavioural and biological predictors [5-8]. Recent studies reported that higher plasma leptin concentrations at baseline [9] as well as lower ghrelin plasma levels [10] may be associated with greater weight loss after an 8-week dietary intervention. In addition, factors such as baseline body weight $[7,11-13]$ and early weight loss in the first weeks of treatment were found associated with greater losses at the end of the study [6, 14-16]. In this regard, we recently observed that initial body weight, early weight loss at week 1 and weight loss at week 3 were strong predictors of total weight loss accounting for $68 \%$ of the variance of the total weight loss $\left(\mathrm{R}^{2}=0.68, \mathrm{p}=0.0001\right)$ during an 8-week low-calorie diet [12]. Further, physical activity level has seemed also to be a significant determinant of weight loss during a period of dietary restriction $[17,18]$.

Attrition rate is an important factor that should be taken into consideration when running a weight loss study. It is established that high attrition rates are a very common problem in obesity trials [19]. Numerous variables thought to be associated with attrition during weight loss interventions have been studied. Most of the published studies reported that higher age, less episodes of depression, non-smoking status, higher levels of physical activity or exercise, weight loss expectations and gender were predictors of attrition [1922], but still most of the variability is unaccounted for, leaving considerable uncertainty about the true causes. Thus, we aimed to identify the early pre-treatment characteristics as well as weight loss at the first weeks of the study that would be strong independent correlates of final weight loss outcome and attrition.

\section{Material and Methods}

Study Design

The NUGENOB project was a randomised, parallel, two-arm, open-label 10-week dietary intervention of two hypo-energetic diets at 8 sites in 7 European countries. The trial was part of a study of gene-nutrient interactions in the physiology and dietary treatment of obesity (www.nugenob.org). Detailed description of the inclusion and exclusion criteria and the methodology of the study were published by Petersen et al. [23].

Participants and Measures

771 obese subjects with an average BMI of $35.6 \mathrm{~kg} / \mathrm{m}^{2}$ were enrolled in the trial (table 1). Subsequently, they were randomised in two parallel dietary groups for a 10-week period as follows: low-fat diet -20 to $25 \%$ of total energy from fat, $-15 \%$ from protein and -60 to $65 \%$ from carbohydrates; high-fat diet -40 to $45 \%$ of total energy from fat, $-15 \%$ from protein and -40 to $45 \%$ from carbohydrates. Both diets were individually tailored to supply subjects with $600 \mathrm{kcal} /$ day less than their individually estimated energy requirement based on an initial resting metabolic rate (as measured by indirect calorimetry) multiplied by 1.3 [23]. Body weight was measured on calibrated scales. Waist and hip circumferences as well as height were measured. Body composition (fat mass and fat-free mass) was assessed by multi- 
Handjieva-Darlenska et al.: Clinical Correlates of Weight Loss and Attrition During a

10-Week Dietary Intervention Study: Results from the NUGENOB Project

Table 1. Baseline subject characteristics at randomisation and weight loss (kg) in different time points. Whenever negative value is used for weight reduction it stands for weight gain

\begin{tabular}{llllll}
\hline & \multicolumn{2}{l}{ Low-fat diet $(\mathrm{n}=389)$} & & \multicolumn{2}{l}{ High-fat diet $(\mathrm{n}=382)$} \\
\cline { 2 - 3 } & mean \pm SEM & range & & mean \pm SEM & range \\
\hline Age, years & $37.0 \pm 0.4$ & $20-51$ & & $37.2 \pm 0.4$ & $20-51$ \\
Body weight, kg & $100.2 \pm 0.9$ & $67.5-168.6$ & & $100.9 \pm 0.8$ & $66.8-188.9$ \\
Height, $\mathrm{m}$ & $1.68 \pm 0.005$ & $1.43-1.97$ & & $1.68 \pm 0.004$ & $1.48-1.93$ \\
BMI, $\mathrm{kg} / \mathrm{m}^{2}$ & $35.6 \pm 0.3$ & $26.4-56.5$ & & $35.6 \pm 0.2$ & $28.1-66.1$ \\
Waist circumference, cm & $106.0 \pm 0.7$ & $81.5-154.7$ & & $106.2 \pm 0.7$ & $76.0-155.0$ \\
Hip circumference, cm & $119.2 \pm 0.5$ & $96.3-159.0$ & & $119.6 \pm 0.5$ & $96.6-185.9$ \\
WHR & $0.89 \pm 0.005$ & $0.68-1.16$ & & $0.89 \pm 0.005$ & $0.67-1.16$ \\
Fat mass, kg & $40.9 \pm 0.6$ & $15.6-83.7$ & & $41.4 \pm 0.6$ & $18.3-116.3$ \\
Fat-free mass, kg & $59.3 \pm 0.6$ & $39.5-98.6$ & & $59.7 \pm 0.6$ & $35.6-94.0$ \\
Body fat, \% & $40.5 \pm 0.4$ & $18.8-59.0$ & & $40.8 \pm 0.4$ & $18.6-61.6$ \\
Weight loss, kg & & & & & \\
$\quad$ Week 1 (early) & $0.95 \pm 0.06$ & -2.7 to 4.8 & & $0.91 \pm 0.06$ & -3.1 to 5.5 \\
$\quad$ Week 5 (half-way) & $4.3 \pm 0.1$ & -2.6 to 13.1 & & $3.8 \pm 0.1$ & -1.2 to 10.5 \\
$\quad$ Week 10 (final) & $6.9 \pm 0.2$ & -2.4 to 16.7 & $6.7 \pm 0.2$ & -4.0 to 18.4 \\
\hline
\end{tabular}

frequency bio-electrical impedance analysis (Bodystat ${ }^{\circledR}$, QuadScan 4000, Isle of Man, British Isles). All measurements were based on NUGENOB standardised operation procedures followed by all investigators in all centres (www.nugenob.org).

\section{Statistical Analysis}

Statistical analyses were conducted using the Statistical Package for the Social Sciences (version 13.0; SPSS Inc, Chicago, IL, USA). Descriptive data are shown as mean \pm SEM. Statistical significance was assigned at $\mathrm{p}<0.05$. Distribution of data was checked for normality by applying the one-sample Kolmogorov-Smirnov test. Correlates included baseline characteristics (e.g. age, gender, body weight, height, BMI, waist and hip circumferences, waist-to-hip ratio, fat mass, and fat-free mass), and body weight losses at week 1 (early weight loss) and at week 5 (half-way weight loss). The outcome variables were weight change $(\mathrm{kg})$ at week 10 and attrition during the 10 -week dietary trial. Attrition was defined as leaving the study at any time before week 10 . Correlation analyses were carried out to examine the relationship between baseline characteristics, early (week 1) and half-way (week 5) weight losses and the final weight loss outcome at week 10 using the Spearman's rho correlation coefficient. In order to find out which independent variables would be associated with weight loss outcome at week 10, we constructed a linear model, which included weight loss at week 10 as dependent variable, centre and age as adjustment factors and as covariates those variables that were shown significantly associated with weight loss a week 10 in univariate analyses, namely gender, baseline body weight, height, BMI, waist and hip circumferences, waist-to-hip ratio as well as fat mass and fat-free mass. In addition, the identified correlates and early weight loss and half-way weight loss were successively tested in multivariate regression models adjusted for centre and age to evaluate their impact on the final weight change. Logistic regression analyses were used to identify variables associated with attrition. Significant risk of drop-out was expressed as an odds ratio (OR) with $95 \%$ confidence interval (CI).

In order to explore the effect of early weight loss (week 1) and half-way weight loss (week 5) we applied sensitivity and specificity analyses with a target of $10 \%$ final weight loss. Early-weight loss cutpoints were set at $\geq 1 \mathrm{~kg}$ and $\geq 2 \mathrm{~kg}$ and half-way cutpoints at $\geq 4 \mathrm{~kg}$ and $\geq 5 \mathrm{~kg}$, and the sensitivity, specificity as well as positive predictive and negative predictive values of each of these were calculated. In this analysis, the sensitivity showed the relative proportion of responders (at least $10 \%$ weight loss) who achieved the early and half-way weight losses, whereas the specificity was the relative proportion of nonresponders who did not achieve the early and half-way weight losses. We also calculated the predictive values of each of the targets to identify which was most strongly associated with achieving or failing to achieve weight loss of at least $10 \%$ of initial body weight at week 10 . 
Table 2. Simple correlation between weight loss (week 10) and baseline characteristics (correlation coefficients and $\mathrm{p}$ values $)^{\mathrm{a}}$
Handjieva-Darlenska et al.: Clinical Correlates of Weight Loss and Attrition During a 10-Week Dietary Intervention Study: Results from the NUGENOB Project

\begin{tabular}{lll}
\hline & \multicolumn{2}{l}{ Spearman's rho (p value) } \\
\cline { 2 - 3 } & $\begin{array}{l}\text { low-fat diet } \\
(\mathrm{N}=336)\end{array}$ & $\begin{array}{l}\text { high-fat diet } \\
(\mathrm{N}=312)\end{array}$ \\
\hline Age, years & $0.11(0.03)$ & $-0.03(0.63)$ \\
Gender & $0.13(0.02)$ & $0.24(<0.001)$ \\
Baseline body weight, kg & $0.08(0.16)$ & $0.19(0.001)$ \\
Height, cm & $0.14(0.01)$ & $0.26(<0.001)$ \\
BMI, kg/m ${ }^{2}$ & $0.01(0.88)$ & $0.02(0.79)$ \\
Waist circumference, cm & $0.09(0.09)$ & $0.14(0.01)$ \\
Hip circumference, cm & $-0.01(0.81)$ & $-0.02(0.71)$ \\
WHR & $0.11(0.04)$ & $0.17(0.003)$ \\
Fat mass, kg & $-0.03(0.63)$ & $-0.03(0.58)$ \\
Fat-free mass, kg & $0.16(0.004)$ & $0.26(<0.001)$ \\
Weight loss, kg & & \\
$\quad$ Week 1 (early) & $0.37(<0.001)$ & $0.47(<0.001)$ \\
\multicolumn{1}{l}{ Week 5 (half-way) } & $0.86(<0.001)$ & $0.86(<0.001)$ \\
\hline
\end{tabular}

${ }^{a}$ Whenever negative value is used for weight reduction, it stands for weight gain.

\section{Results}

The analyses were conducted in the low-fat and high-fat groups separately. Thus, the results are presented for each dietary group. Subject anthropometric and body composition measurements are shown in table 1 . The fat energy per cent during the study was within the targeted interval: $25 \%$ in the low-fat group and $40 \%$ in the high-fat group with a group difference of $16 \%$ (95\% CI 15-17\%). Mean weight loss was $6.9 \mathrm{~kg}$ in the low-fat group, and $6.7 \mathrm{~kg}$ in the high-fat group with no group difference (mean 0.3 (95\% CI -0.2 to 0.8 ) $\mathrm{kg}$ ) (table 1), as previously reported by Petersen et al [23].

In univariate analyses, weight loss at the end of the dietary intervention (week 10) in the low-fat group was positively correlated with age, gender and baseline values of height, fat-free mass and waist-to-hip ratio while no significant correlations with baseline values of body weight, waist and hip circumferences or fat mass were found (table 2). Weight loss at the end of the dietary intervention (week 10) in the high-fat group was positively correlated with gender, baseline values of body weight, height, waist circumference and waist-to-hip ratio (table 2). No significant associations were found for hip circumference, fat mass, fat-free mass or age. The final weight loss (week 10) was positively correlated with early weight loss (week 1) as well as with half-way weight loss (week 5) (table 2).

A linear regression model was constructed with weight loss at week 10 as dependent variable and baseline subject characteristics and early weight loss (week 1) as covariates. The interaction between dietary group and weight loss was not significant. Thus, this analysis has been performed for both dietary groups combined. After adjusting for centre and age, the weight loss $(\mathrm{kg})$ at week 10 was: $6.55+1.27 \times$ early weight loss $(\mathrm{kg})$ at week 1 $+1.35 \times$ gender (where $0=$ female and $1=$ male) $\left(R^{2}=0.28, p<0.001\right)$. Together these determinants explained $28 \%$ of the total variation of the final weight loss (table 3 ).

Then, a second linear regression model was constructed with weight loss at week 10 as dependent variable and baseline subject characteristics and half-way weight loss (week 5) as covariates. The interaction between dietary group and weight loss was not significant. Thus, this analysis has been performed for both dietary groups combined (table 3). The 
Table 3. Independent baseline correlates of weight loss at week 10
DOI: $10.1159 / 000345951$

Handjieva-Darlenska et al.: Clinical Correlates of Weight Loss and Attrition During a 10-Week Dietary Intervention Study: Results from the NUGENOB Project

\begin{tabular}{llll}
\hline & $\beta$ & $\begin{array}{l}\text { Standard } \\
\text { error }\end{array}$ & P value \\
& & & \\
\hline Model $^{*}$ & 1.35 & 0.28 & $<0.001$ \\
$\quad$ Gender** & 1.27 & 0.11 & $<0.001$ \\
$\quad$ Early weight loss (week 1) $^{*}$ & & & \\
\hline $\begin{array}{l}\text { Model* } \\
\text { Gender** }\end{array}$ & 0.42 & 0.16 & 0.009 \\
$\quad$ Half-way weight loss (week 5) & 1.38 & 0.03 & $<0.001$ \\
\hline
\end{tabular}

*The interaction between dietary group and weight loss was not significant $(p=0.26$ and $p=0.41$, respectively). Therefore, the analysis has been performed with dietary groups combined.

** Gender: 0-female; 1-male. The linear model also included intercept, centre and age.

Table 4. Characteristics of selected cut-offs of early weight loss at week 1 and half-way weight loss at week 5 as predictors of $10 \%$ weight loss

\begin{tabular}{|c|c|c|c|c|}
\hline Cut-off values, kg & Sensitivity, $\%$ & Specificity, \% & $\begin{array}{l}\text { Positive predictive } \\
\text { value, } \%\end{array}$ & $\begin{array}{l}\text { Negative predictive } \\
\text { value, } \%\end{array}$ \\
\hline \multicolumn{5}{|c|}{ Early weight loss (week 1) } \\
\hline$\geq 1$ & 73 & 57 & 41 & 84 \\
\hline$\geq 2$ & 32 & 87 & 51 & 76 \\
\hline \multicolumn{5}{|c|}{ Half-way weight loss (week 5) } \\
\hline$\geq 4$ & 92 & 64 & 51 & 95 \\
\hline$\geq 5$ & 76 & 84 & 67 & 90 \\
\hline
\end{tabular}

multiple regression model for the combined group showed that weight loss (kg) at week 10 was: weight loss $(\mathrm{kg})$ at week $10=1.88+1.382 \times$ half-way weight loss $(\mathrm{kg})$ (week 5) +0.42 $\times$ gender (where $0=$ female and $1=$ male) $\left(R^{2}=0.77, p<0.001\right)$. Together, these factors explained $77 \%$ of the total variation of weight loss at week 10 .

The characteristics associated with the selected early and half-way loss cut-offs are summarised in table 4 . The ideal early and half-way weight losses should combine high values of both sensitivity and specificity, but the clinical utility requires high predictive values of the positive and negative level at the time of assessment, i.e. at 1 and 5 weeks. For subjects, losing $\geq 4 \mathrm{~kg}$ at week 5 the positive predictive value was $51 \%$ for achieving $10 \%$ weight loss at week 10 , which shows that those who are successful to achieve a high weight loss are not likely to regain but rather to continue to lose weight in the subsequent weeks. However, for those who failed to achieve $\geq 4 \mathrm{~kg}$ weight loss target at week 5 , the negative predictive value of the test was $95 \%$, which implies high level of certainty that these patients will not achieve the goal of $10 \%$ weight loss. A weight loss of $5 \mathrm{~kg}$ at week 5 appeared to have values rather similar to those described above (table 4). For those subjects who have achieved a weight loss of at least $5 \mathrm{~kg}$ at week 5 during the dietary intervention, the positive predictive power of reaching at least $10 \%$ weight loss at the end of the diet was $67 \%$ and the negative predictive power $90 \%$. 
Drop-out rate was $13.6 \%(n=53)$ in the low-fat group and $18.3 \%(n=70)$ in the high-fat group ( $\mathrm{p}=0.001$ ) [23]. Compared to the low-fat diet, the high-fat diet was associated with greater attrition odds during the 10 -week intervention $(\mathrm{OR}=1.48,95 \% \mathrm{CI}=0.98-2.00)$ after adjusting for centre and gender. No additional effect of the baseline subject characteristics selected in this paper on the likelihood for drop-out was found. In addition, the risk for drop-out was associated with early (week 1) and half-way (week 5) weight losses. Subjects with less weight loss at week 1 showed increased risk for attrition during the 10 -week dietary intervention study $(\mathrm{OR}=0.73,95 \% \mathrm{CI}=0.60-0.88)$ when adjusted for centre and dietary group. Attrition likelihood was also predicted by half-way weight loss (week 5). It was established that the decreased half-way weight loss increased the risk for drop-out during the dietary intervention $(\mathrm{OR}=0.73,95 \% \mathrm{CI}=0.61-0.87)$. When early weight loss was entered into the model, it did not predict attrition, whereas half-way weight loss remained significant $(\mathrm{OR}=0.66,95 \% \mathrm{CI}=0.53-0.83 ; \mathrm{p}<0.001)$ when adjusted for centre, gender and dietary group.

\section{Discussion}

We investigated correlates of weight loss outcome after a 10-week dietary intervention study in obese subjects included in a multicentre European trial. Although numerous determinants of weight loss have been proposed [5, 13, 21, 24-26], the issue is not settled yet. The major findings of this study were that easily obtained measures such as body weight change throughout the programme and gender were successfully associated with the final weight loss outcome. Early weight loss emerged to be a correlate of further weight reduction. This finding is consistent with previous studies investigating the effect of initial weight loss on short- or long-term dietary-induced body weight changes $[6,12,15,16,19,27,28]$. That early weight loss could be used as relevant prognostic marker was emphasised in a review by Astrup and Rossner [14]. As expected, the present study showed that also half-way weight loss could also be regarded as a determinant of final weight outcome, providing indications for adjustment of the weight loss programme.

In our study, men showed a greater body weight reduction ( 8.2 and $7.6 \mathrm{~kg}$ ) than women (6.1 and $6.7 \mathrm{~kg}$ ) in both low- and high-fat groups. This was previously found also by Lafortuna et al. [29] and Sartorio et al. [30]. Obese men and women have notably different body composition, which may contribute to having differentweight loss ability. Under the same prescribed level of energy intake (-600 kcal/day), it is well known that subjects with higher body mass and higher energy expenditure will achieve a greater energy gap and lose weight faster [12]. A large body of evidence has reported the contrary notion that women were more compliant and motivated in participating in weight loss programmes [25, 31, 32]. However, according to Linne et al. [33], men were more realistic in their weight goals and thus more successful in losing body weight.

This study has revealed that a weight loss of less than $4 \mathrm{~kg}$ in week 5 during a diet could predict a failure in the final weight loss outcome of at least $10 \%$ weight loss. Thus, this outcome of assessment at 5 weeks could then be used as a justification of reinforcement of the dietary regimen, to change to other treatment options (i.e. pharmacotherapy) or to discontinue treatment. However, the predictive value of having achieved $4 \mathrm{~kg}$ at week 5 is much less and by itself not particularly helpful; so more information is needed to predict success. In clinical practice, the 5-week period of observation can be justified with the rationale that patients have different motivation level and self-confidence during half-way in the weight loss attempt. One could suggest that the propensity of losing weight is very much dependent on the self-motivation. The more body weight the subject loses, the better 
is the final weight loss result during a dietary intervention study. This was shown previously by Handjieva-Darlenska et al. [12]. The authors suggested that an early weight loss of at least $2.6 \mathrm{~kg}$ at week 1 during a low-calorie diet could be used as a predictor of later success.

In recent years, considerable attention has been given to the attrition rate during weight loss programmes [19, 20, 34, 35]. It is of a great clinical importance to identify easily measured variables that could predict attrition rate. Some of the variables that have been found to determine attrition were psychological factors such as depression, stress and weight loss expectations [20,31,36]. Others were demographic [34, 37] and behavioural factors $[35,37]$. This study revealed that a high-fat diet was associated with greater attrition odds during the 10 -week dietary intervention period $(\mathrm{OR}=1.48,95 \% \mathrm{CI}=0.98-2.0)$. One could suggest that the composition of the prescribed diet for obesity treatment could determine the overall success of the weight loss programme. Our study also demonstrated that lower early and half-way weight losses were strong correlates of increased attrition rate during 10-week dietary intervention study $(\mathrm{OR}=0.73,95 \% \mathrm{CI}=0.60-0.89$ and $\mathrm{OR}=$ $0.73 ; 95 \% \mathrm{CI}=0.61-0.87$, respectively).

\section{Conclusion}

The main goal of this study was to identify factors that could be associated with weight loss outcome and attrition rate during 10-week dietary intervention study. The results demonstrate that early weight loss at week 1 and half-way weight loss at week 5 were correlates of final weight loss outcome. Furthermore, gender plays a key role in determining body weight reduction in obese subjects. Taken together, these three factors may be used in the obesity day-care practice and could improve the development of adequate prognostic models for weight loss. More importantly the information could lead to individualised reinforcements of counselling in these subjects identified at risk of lower weight loss. Furthermore, a weight loss of less than $4 \mathrm{~kg}$ during a diet could be easily used as a prognostic criterion for failure in further weight loss. In addition, high-fat diet as well as lower early and half-way weight losses were identified as strong correlates of drop-out during the intervention study. Finally, we conclude that male gender, early weight loss and half-way weight loss are easily detectable factors that might be used as prognostic tool of weight loss and attrition.

\section{Disclosure Statement}

The authors have no conflicts of interest pertaining to this paper.

\section{References}

1 Pi-Sunyer FX: Health implications of obesity. Am J Clin Nutr 1991;53(6 suppl):1595S-1603S.

2 Burton BT, Foster WR: Health implications of obesity: an NIH Consensus Development Conference. J Am Diet Assoc 1985;85:1117-1121.

3 Organization WH: Obesity: Preventing and Managing the Global Epidemic; in Report of a WHO Consultation. Geneva, Switzerland, 2000.

4 Prentice AM, Jebb SA, Goldberg GR, Coward WA, Murgatroyd PR, Poppitt SD, Cole TJ: Effects of weight cycling on body composition. Am J Clin Nutr 1992;56(1 suppl):209S-216S.

5 Astrup A, Buemann B, Gluud C, Bennett P, Tjur T, Christensen N: Prognostic markers for diet-induced weight loss in obese women. Int J Obes Relat Metab Disord 1995;19:275-278.

6 Wadden TA, Foster GD, Wang J, Pierson RN, Yang MU, Moreland K, Stunkard AJ, VanItallie TB: Clinical correlates of short- and long-term weight loss. Am J Clin Nutr 1992, 56(1 suppl):271S-274S. 
7 Hansen D, Astrup A, Toubro S, Finer N, Kopelman P, Hilsted J, Rossner S, Saris W, Van Gaal L, James W, et al: Predictors of weight loss and maintenance during 2 years of treatment by sibutramine in obesity. Results from the European multi-centre STORM trial. Sibutramine Trial of Obesity Reduction and Maintenance. Int J Obes Relat Metab Disord 2001;25:496-501.

8 Dubbert PM, Wilson GT: Goal-setting and spouse involvement in the treatment of obesity. Behav Res Ther 1984;22:227-242.

9 Ramel A, Arnarson A, Parra D, Kiely M, Bandarra NM, Martinez JA, Thorsdottir I: Gender difference in the prediction of weight loss by leptin among overweight adults. Ann Nutr Metab;56:190-197.

$\checkmark 10$ Crujeiras AB, Goyenechea E, Abete I, Lage M, Carreira MC, Martinez JA, Casanueva FF: Weight regain after a diet-induced loss is predicted by higher baseline leptin and lower ghrelin plasma levels. J Clin Endocrinol Metab 2010;95:5037-5044.

-11 Larsen JK, Geenen R, Maas C, de Wit P, van Antwerpen T, Brand N, van Ramshorst B: Personality as a predictor of weight loss maintenance after surgery for morbid obesity. Obes Res 2004;12:1828-1834.

-12 Handjieva-Darlenska T, Handjiev S, Larsen TM, van Baak MA, Jebb S, Papadaki A, Pfeiffer AF, Martinez JA, Kunesova M, Holst C, et al: Initial weight loss on an 800-kcal diet as a predictor of weight loss success after 8 weeks: the Diogenes study. Eur J Clin Nutr 2010;64:994-999.

13 Braet C: Patient characteristics as predictors of weight loss after an obesity treatment for children. Obesity (Silver Spring) 2006;14:148-155.

14 Astrup A, Rossner S: Lessons from obesity management programmes: greater initial weight loss improves long-term maintenance. Obes Rev 2000;1:17-19.

15 Dhurandhar NV, Blank RC, Schumacher D, Atkinson RL: Initial weight loss as a predictor of response to obesity drugs. Int J Obes Relat Metab Disord 1999;23:1333-1336.

16 Finer N, Ryan DH, Renz CL, Hewkin AC: Prediction of response to sibutramine therapy in obese non-diabetic and diabetic patients. Diabetes Obes Metab 2006;8:206-213.

17 van Baak MA, van Mil E, Astrup AV, Finer N, Van Gaal LF, Hilsted J, Kopelman PG, Rossner S, James WP, Saris WH: Leisure-time activity is an important determinant of long-term weight maintenance after weight loss in the Sibutramine Trial on Obesity Reduction and Maintenance (STORM trial). Am J Clin Nutr 2003;78: 209-214.

18 Jeffery RW, Wing RR, Sherwood NE, Tate DF: Physical activity and weight loss: does prescribing higher physical activity goals improve outcome? Am J Clin Nutr 2003;78:684-689.

19 Fabricatore AN, Wadden TA, Moore RH, Butryn ML, Heymsfield SB, Nguyen AM: Predictors of attrition and weight loss success: results from a randomized controlled trial. Behav Res Ther 2009;47:685-691.

20 Honas JJ, Early JL, Frederickson DD, O’Brien MS: Predictors of attrition in a large clinic-based weight-loss program. Obes Res 2003;11:888-894.

-21 Anton SD, Martin CK, Redman L, York-Crowe E, Heilbronn LK, Han H, Williamson DA, Ravussin E: Psychosocial and behavioral pre-treatment predictors of weight loss outcomes. Eat Weight Disord 2008;13:30-37.

$\checkmark 22$ Dalle Grave R, Calugi S, Molinari E, Petroni ML, Bondi M, Compare A, Marchesini G: Weight loss expectations in obese patients and treatment attrition: an observational multicenter study. Obes Res 2005;13:19611969.

-23 Petersen M, Taylor MA, Saris WH, Verdich C, Toubro S, Macdonald I, Rossner S, Stich V, Guy-Grand B, Langin $D$ et al: Randomized, multi-center trial of two hypo-energetic diets in obese subjects: high- versus low-fat content. Int J Obes (Lond) 2006;30:552-560.

24 Anderson JW, Grant L, Gotthelf L, Stifler LT: Weight loss and long-term follow-up of severely obese individuals treated with an intense behavioral program. Int J Obes (Lond) 2007;31:488-493.

-25 Black DR, Lantz CE: Spouse involvement and a possible long-term follow-up trap in weight loss. Behav Res Ther 1984;22:557-562.

-26 Hainer V, Kunesova M, Bellisle F, Hill M, Braunerova R, Wagenknecht M: Psychobehavioral and nutritional predictors of weight loss in obese women treated with sibutramine. Int J Obes (Lond) 2005;29:208-216.

-27 Hollis JF, Gullion CM, Stevens VJ, Brantley PJ, Appel LJ, Ard JD, Champagne CM, Dalcin A, Erlinger TP, Funk $\mathrm{K}$, et al: Weight loss during the intensive intervention phase of the weight-loss maintenance trial. Am J Prev Med 2008;35:118-126.

28 Elfhag K, Rossner S: Initial weight loss is the best predictor for success in obesity treatment and sociodemographic liabilities increase risk for drop-out. Patient Educ Couns 2010;79:361-366.

29 Lafortuna CL, Maffiuletti NA, Agosti F, Sartorio A: Gender variations of body composition, muscle strength and power output in morbid obesity. Int J Obes (Lond) 2005;29:833-841.

-30 Sartorio A, Maffiuletti NA, Agosti F, Lafortuna CL: Gender-related changes in body composition, muscle strength and power output after a short-term multidisciplinary weight loss intervention in morbid obesity. J Endocrinol Invest 2005;28:494-501.

-31 Teixeira PJ, Going SB, Houtkooper LB, Cussler EC, Metcalfe LL, Blew RM, Sardinha LB, Lohman TG: Pretreatment predictors of attrition and successful weight management in women. Int J Obes Relat Metab Disord 2004;28:1124-1133.

-32 Wing RR, Marcus MD, Epstein LH, Jawad A: A 'family-based' approach to the treatment of obese type II diabetic patients. J Consult Clin Psychol 1991;59:156-162.

33 Linne Y, Hemmingsson E, Adolfsson B, Ramsten J, Rossner S: Patient expectations of obesity treatment - the experience from a day-care unit. Int J Obes Relat Metab Disord 2002;26:739-741. 
-34 Handjieva-Darlenska T, Handjiev S, Larsen TM, van Baak MA, Lindroos AK, Papadaki A, Pfeiffer AFH, Martinez JA, Kunesova M, Holst C, Saris WHM, Astrup A: Predictors of weight loss maintenance and attrition during a 6 months dietary intervention period: results from the DiOGenes study. Clin Obes 2011;1:62-68.

-35 Davis MJ, Addis ME: Predictors of attrition from behavioral medicine treatments. Ann Behav Med 1999;21: 339-349.

-36 Jones F, Harris P, Waller H, Coggins A: Adherence to an exercise prescription scheme: the role of expectations, self-efficacy, stage of change and psychological well-being. Br J Health Psychol 2005;10:359-378.

-37 Wadden TA, Stunkard AJ: Controlled trial of very low calorie diet, behavior therapy, and their combination in the treatment of obesity. J Consult Clin Psychol 1986;54:482-488. 